\title{
Aboveground Competition and Herbivory Overpower Plant-Soil Feedback Contributions to Succession in a Remediated Grassland
}

\author{
Lee H. Dietterich ${ }^{1,2 *}$, Amy Li ${ }^{1,3}$, Sarah M. Garvey ${ }^{1,4}$ and Brenda B. Casper ${ }^{1}$ \\ ${ }^{1}$ Department of Biology, University of Pennsylvania, Philadelphia, PA, United States, ${ }^{2}$ Department of Ecosystem Science and \\ Sustainability, Warner College of Natural Resources, Colorado State University, Fort Collins, CO, United States, ${ }^{3}$ Department \\ of Environmental Science and Public Policy, Harvard University, Cambridge, MA, United States, ${ }^{4}$ Department of Earth \& \\ Environment, Boston University, Boston, MA, United States
}

OPEN ACCESS

Edited by:

Martijn Bezemer,

Netherlands Institute of Ecology (NIOO-KNAW), Netherlands

Reviewed by:

Jonathan Richard De Long, Wageningen University and

Research, Netherlands

Robin Heinen,

Netherlands Institute of Ecology (NIOO-KNAW), Netherlands Jingying Jing China Agricultural University (CAU), China

*Correspondence:

Lee H. Dietterich lee.dietterich@gmail.com

Specialty section:

This article was submitted to Behavioral and Evolutionary Ecology,

a section of the journal

Frontiers in Ecology and Evolution

Received: 05 August 2019 Accepted: 13 November 2019 Published: 29 November 2019

Citation:

Dietterich LH, Li A, Garvey SM and Casper BB (2019) Aboveground Competition and Herbivory Overpower Plant-Soil Feedback Contributions to Succession in a Remediated Grassland. Front. Ecol. Evol. 7:459. doi: 10.3389/fevo.2019.00459
Plant-soil feedback (PSF) can provide a driving force during ecological succession by altering soil properties in ways that benefit or disadvantage other species in the successional sequence. Succession may be inevitable in disturbed sites remediated by planting early successional species, but information on PSF in such settings is lacking. We investigated whether gray birch (Betula populifolia), a native species but strong invader, alters succession from grassland to deciduous forest at a site contaminated with zinc, lead, and cadmium. We investigated PSF within the context of competition, herbivory, and soil contaminants, and evaluated whether gray birch, as a high metal accumulator, engages in elemental allelopathy, poisoning other species through its metal-contaminated leaf litter. We assessed the effects of gray birch on neighboring plant community structure, soil chemistry, fungal root symbionts, and the germination, growth, and herbivory of seedlings of black oak (Quercus velutina) and sugar maple (Acer saccharum), two tree species expected to follow gray birch in succession. Gray birch was associated with increased diversity in its neighborhood grassland community, increased herbivory on black oak seedlings, and influenced colonization by fungal root symbionts in both species. Seedling biomass was correlated with colonization by ectomycorrhizal fungi in black oak, but not with arbuscular mycorrhizal or dark septate fungal colonization in sugar maple. Gray birch had no effect on maple seedling performance or soil chemistry, and a small effect on black oak performance in the absence of aboveground competition. We found little evidence consistent with elemental allelopathy. Black oak and sugar maple seedlings responded more strongly to variation in soil nutrients than soil heavy metals, and they maintained leaf metal concentration profiles markedly different from those in their soils. We conclude that gray birch alters its environment in ways that could promote establishment and succession of woody species, potentially favoring those that are ectomycorrhizal, but most effects of PSF are overpowered by aboveground competition, herbivory, and/or existing abiotic soil factors. This study well illustrates why the potential for PSF to affect plant performance 
and community structure must be examined within the context of other ecological processes. Such a broad understanding can inform decisions made in the remediation and management of disturbed sites, and our understanding of plant succession and coexistence in general.

Keywords: competition, heavy metals, herbivory, plant-soil feedback, succession, remediation, restoration

\section{INTRODUCTION}

Succession is the process by which the species composition of ecological communities changes over time, in ways that are often orderly and directional (Connell and Slatyer, 1977). In terrestrial systems, plant-soil feedback (PSF) is a driver of plant species replacements (Connell and Slatyer, 1977; Bauer et al., 2015; Wubs and Bezemer, 2017), and can either speed or slow succession, depending on whether plant-induced soil alterations improve or worsen conditions for contemporary species relative to later arriving species (Bever et al., 1997; Reynolds et al., 2003; Kardol et al., 2006; Castle et al., 2016; Lozano et al., 2018; Crawford et al., 2019). PSFs can act via soil organisms, including pathogens and symbionts such as mycorrhizal fungi, as well as any number of chemical or physical soil properties (Ehrenfeld et al., 2005; Png et al., 2018; Bennett and Klironomos, 2019). While PSFs have been shown broadly to be involved in ecological succession (Kardol et al., 2006; Kulmatiski et al., 2008; Bauer et al., 2015), connecting specific feedback mechanisms to succession remains rare in the literature, and calls are made for more such studies and for more field studies of PSFs in general (Van Der Putten et al., 2013, 2016; De Long et al., 2018).

Field studies are essential for evaluating the importance of PSF in the presence of other prevalent ecological processes affecting a species' performance, such as plant-plant competition and herbivory (Casper and Castelli, 2007; Heinze and Joshi, 2017). Both competition and herbivory have the potential to augment or reduce effects of PSF, based on the strength of these other processes and whether their effect on plant performance is in the same or opposite direction as that of PSF (Casper and Castelli, 2007; Lekberg et al., 2018; Heinze et al., 2019). Conversely, PSF effects on plant performance could indirectly alter a plant's susceptibility to herbivory based on information that herbivory levels can vary with mycorrhizal status (Gehring and Bennett, 2009; Koricheva et al., 2009), leaf nutritional quality (Ayres et al., 1997), or plant vigor (Cornelissen et al., 2008), and evidence that soil biota can influence plant nutritional quality (Kos et al., 2015) and herbivory defenses (Kostenko et al., 2012; Zhu et al., 2018). PSF may contribute to plant-plant competition directly through altered soil characteristics or indirectly (Hortal et al., 2017; Bezemer et al., 2018) since competitive ability is usually related to plant size (Weiner and Thomas, 1986).

Understanding how plant communities change over time and which mechanisms underlie these changes is deeply important for managing ecosystems and particularly pertinent for previously disturbed sites undergoing restoration, where installed vegetation may represent an early successional stage. Grasses and other early successional plants are often planted on abandoned mines or metal-polluted sites in order to curtail erosion and leaching, achieve quick phytostabilization through ground cover, and create a surface soil enriched in organic matter (Turnau et al., 2008; Bolan et al., 2011), even in regions where woody plants are the expected successional climax (Turnau et al., 2010; Zhang et al., 2012). We need to know more about succession in these systems and the possible role of PSFs, particularly in heavy metal contaminated soils (Krumins et al., 2015).

Heavy metal soils hold the potential for a particular PSF mechanism called elemental allelopathy. The idea is that plants with high leaf metal uptake create allelopathy (Inderiit et al., 2011) when their contaminated leaf litter locally increases soil metal concentrations to the detriment of less metal tolerant plants and/or soil microbes growing nearby (Baker and Brooks, 1989; Wilson and Agnew, 1992; Boyd and Martens, 1998). Some field studies have found elevated levels of metal contaminants around hyperaccumulating plants, sometimes with negative effects on other species, consistent with elemental allelopathy (Boyd and Jaffré, 2001; Mehdawi et al., 2011; Jaffe et al., 2017), but most cannot eliminate alternative explanations (Morris et al., 2009; Mehdawi et al., 2011).

We looked for evidence of PSF and elemental allelopathy in particular during succession from grassland to deciduous forest at a revegetated site. The site was historically mostly forested but was then severely contaminated and devegetated by $\mathrm{Zn}, \mathrm{Pb}$, $\mathrm{Cd}$, and $\mathrm{SO}_{\mathrm{x}}$ emissions from two zinc smelters operating for approximately 80 years, with the combination of metal pollution and acidity from $\mathrm{SO}_{\mathrm{x}}$ likely responsible for most plant deaths (Buchauer, 1973; Jordan, 1975; EPA, 2007a,b). Land managers chose a phytostabilization approach and planted primarily $\mathrm{C}_{4}$ grasses with low metal uptake rates (EPA, 2007a,b). Among the most successful species that have since encroached from forest remnants or colonized de novo (Dietterich and Casper, 2017) is gray birch (Betula populifolia), a native pioneer tree that accumulates high foliar concentrations of the metal pollutants (Gallagher et al., 2011).

Our main goal was to determine whether gray birch affects succession through PSF at this revegetated, heavy metal polluted site. We examined how gray birch affects local plant community structure; soil organic matter, metal, and nutrient concentrations; and soil temperature and moisture. To address PSF, we crossed soils conditioned by either gray birch or grasses with the presence or absence of aboveground competition in the field to identify any interactions between these two factors in affecting succession. In particular, we examined seed germination and seedling size, root colonization by fungal symbionts, herbivory levels, and plant metal uptake of two later successional tree 
species, black oak (Quercus velutina, Fagaceae) and sugar maple (Acer saccharum, Sapindaceae).

Because of gray birch's high metal uptake, we predicted (1) lower seedling growth under birches than grasses, but higher growth in plots where aboveground competition was removed. Because gray birch and black oak both associate with ectomycorrhizal fungi (ECM) while the grasses and sugar maple are only colonized by arbuscular mycorrhizal fungi (AMF) (Harley and Harley, 1987; Dickie et al., 2001; Wang and Qiu, 2006), we predicted (2) black oak would have greater ECM colonization in soils conditioned by gray birch, sugar maple would have more AMF colonization in soils influenced primarily by grasses, and increased root colonization would translate to increased plant growth. To examine the effects of PSF and competition in the context of standing variation in soil metal contamination, we further explored whether spatial variation in soil contaminant and nutrient concentrations explained variation in seedling performance or leaf chemistry, independent of our experimental treatments. We predicted (3) strong relationships between soil contaminant concentrations, plant growth, and leaf contaminant concentrations, on the premise that the presence and availability of metals in the soil would shape plant uptake of those metals. Finally, through the field experiment and a companion greenhouse experiment, we evaluated (4) whether gray birch engages in elemental allelopathy.

\section{MATERIALS AND METHODS}

Our study was based in the portion of the Palmerton Zinc Superfund Site (Palmerton, PA, USA) owned and managed by the Lehigh Gap Nature Center. The large area ( $>800 \mathrm{ha}$ ) and steep, rocky terrain made removing the metal contaminants unfeasible (EPA, 2007a,b). To remediate the devegetation and high levels of soil metal contaminants, land managers applied fertilizer and compost to inoculate the soil with microbes, including decomposers and mycorrhizal fungi. They planted $\mathrm{C}_{4}$ grasses, known to have low metal uptake rates, with the goal of creating an organic enriched surface layer, sequestering the metals away from humans and the rest of the food web (EPA, 2007a,b). The planted grasses remain abundant but now represent a minority of the site's species, as many others have encroached from forest remnants or colonized since the revegetation efforts (Dietterich and Casper, 2017). Gray birch, the most striking colonizer, is spreading rapidly and forming dense stands.

Our field experiment to determine how seed germination and seedling performance of black oak and sugar maple respond to grass vs. birch, as two dominant vegetation types, was set up from May 2014 to September 2015. At each of 10 locations where grassland communities grew in close proximity to dense gray birch stands, we established four $1.5 \times 3.0 \mathrm{~m}$ experimental plots; two dominated by gray birch and two dominated by the grasses. At each location, to examine possible interactive effects of aboveground competition and vegetation type, every $\sim 2$ weeks during the growing season, we clipped and removed all aboveground vegetation from one plot of each vegetation type while leaving the other intact. We chose not to remove belowground vegetation in order to preserve soil structure and possible variation in soil chemistry with depth.

\section{Gray Birch Effects on Community Structure and Soil Characteristics}

Before setting up the experiment, we evaluated plant community structure and soil nutrients, metal contaminants, and organic matter. In a May 2014 census, we identified all plants, most to species, and visually estimated their percent cover within each plot. Because the plots' dominant grasses could not consistently be identified to species at that time of year, we grouped them into a single taxon for analysis. We examined total cover of the birch and grasses as well as cover, species richness, and Shannon diversity of newly colonizing species apart from birch and grasses.

To investigate soil chemistry, we collected $\sim 100 \mathrm{~g}$ of surface soil (primarily organic horizon material from the top $\sim 10 \mathrm{~cm}$ of soil) at the center of each plot using a clean trowel. Soils were air-dried in the lab and sieved to $2 \mathrm{~mm}$. We used inductively coupled plasma optical emissions spectroscopy (ICP-OES; details below) to measure concentrations of the nutrients $\mathrm{Ca}, \mathrm{Mg}$, and $\mathrm{K}$, the known contaminants $\mathrm{Zn}, \mathrm{Cd}$, and $\mathrm{Pb}$, and the heavy metals $\mathrm{Cu}, \mathrm{Mn}$, and $\mathrm{Ni}$, which were not expected to be enriched in the site. The procedure yields total extractible concentrations of these metals and nutrients, which we interpret as the amount of the metals and nutrients a long-lived plant may have access to in its lifetime, but more than would be bioavailable to a plant at any given time. We also measured soil organic matter content as percent loss on ignition (LOI).

To further characterize growing conditions, in the second growing season, we periodically measured soil moisture and temperature at three locations in each plot with a WET-2 sensor connected to an $\mathrm{HH} 2$ moisture meter (Delta-T Devices Ltd, Cambridge, UK). We measured leaf area index as a proxy for shading intensity with a CI-110 Plant Canopy Imager (CID Bio-Science, Inc., Camas, WA, USA).

\section{Gray Birch and Abovegound Competition Impacts on Tree Species Establishment, Mycorrhizal Colonization, and Leaf Metal Content}

We planted six bare-root 1-2 year old seedlings each of black oak and sugar maple (Musser Forests, Indiana, PA, USA) into each plot. For each seedling, we dug a hole with shovels and trowels, put the seedling into the hole, and backfilled the excavated soil up to the top of the root collar. Each seedling received 10-20 mL of water at planting and one or two days later, but otherwise were irrigated by rainfall. To protect seedlings from deer, we used plastic mesh tubes (Forestry Suppliers, Jackson, MS, USA, Stock No. 17048), supported by wooden garden stakes and cable ties. Every 2-3 weeks during both growing seasons, we re-cleared all aboveground vegetation from cleared plots and examined all planted tree seedlings, adjusting displaced protective tubes as necessary. In spring 2014, we also assessed germination by planting 20 cold-stratified seeds of each species (Sheffield's Seed Co., Inc., Locke, NY, USA) near the center of each plot and counting seedling emergence after nine weeks. Seeds were planted under a $\sim 40 \times 40 \mathrm{~cm}$ plastic $\sim 0.5 \mathrm{~cm}$ mesh to reduce seed herbivory and aid in seedling recovery.

We measured seedling height at planting and again at harvest, where we conducted additional size and biomass measurements 
at the end of the second growing season. We separated seedlings into aboveground and belowground parts by clipping at the top of the root collar. We recorded aboveground plant height, fresh and dry leaf biomass, dry stem biomass, leaf area, number of leaves, and the length of apical and lateral branches grown during the current and previous growing seasons. We estimated whether leaf herbivory was absent, mild (5-20\% of leaf area), moderate (20$50 \%$ of leaf area), or severe ( $>50 \%$ of leaf area) after Johnson et al. (2016). We restricted our analysis to herbivory that appeared to be due to insects based on the pattern of leaf damage. We saw evidence of deer herbivory, including stem and leaf damage in the shape of a single large bite mark, as well as live deer and deer scat in the area. We did not analyze deer herbivory because it was impossible to know how many leaves were missing.

We also measured root biomass and fungal colonization. We washed roots thoroughly with tap water and recorded the fresh weight of the whole root system. For all 228 black oak seedlings harvested, we recorded percent colonization by ECM as the proportion of colonized root tips out of a representative sample of at least 50 root tips, unless fewer were available. For sugar maples, we removed and weighed sub-samples of fine roots to clear and stain for colonization by AMF and dark septate endophytes (DSE). We estimated dry biomass of roots used for endophyte colonization by obtaining wet and dry weights of additional fine root sub-samples. We dried root systems at $60^{\circ} \mathrm{C}$ for at least $48 \mathrm{~h}$, then manually separated and recorded the dry biomass of fine $(\leq 1 \mathrm{~mm}$ diameter) and coarse ( $>1 \mathrm{~mm}$ diameter) roots.

To quantify AMF and DSE colonization in sugar maple, subsamples of fine roots were cleared in $10 \% \mathrm{KOH}$ for $12-24 \mathrm{~h}$ or as needed to remove abundant dark pigments, bleached in 9:1 household $\mathrm{H}_{2} \mathrm{O}_{2}$ : household $\mathrm{NH}_{3}$, acidified in $5 \% \mathrm{HCl}$ for 15-30 min, and stained in hot 0.01\% Trypan blue in 1:1:1 lactic acid: glycerol: water. For each of 44 seedlings sampled at random, at least 10 root segments at least $1 \mathrm{~cm}$ long were mounted in parallel on a microscope slide and fixed with polyvinyl lactic acid glycerol (INVAM, 2014). We recorded percent colonization of AMF and DSE by assessing the presence or absence of their structures on each 1-mm section of each root segment (modified from McGonigle et al., 1990).

We measured metal concentrations in leaves collected at the end of the first growing season, in September 2014. We collected one leaf from each planted seedling with three leaves and two leaves from each seedling with four leaves or more, and combined them by species and plot. We washed leaves thoroughly with tap water, dried them at $60^{\circ} \mathrm{C}$ for at least $48 \mathrm{~h}$, and ground them with mortar and pestle using liquid nitrogen as necessary. We then weighed $0.25-0.50 \mathrm{~g}$ of the samples into ceramic crucibles, ashed them in a muffle furnace at $475^{\circ} \mathrm{C}$ for at least $4 \mathrm{~h}$, and weighed them again to estimate organic matter content by LOI. We digested the residue in $2 \mathrm{~mL}$ concentrated $\mathrm{HCl}$ for $10 \mathrm{~min}$ at $90-100^{\circ} \mathrm{C}$. Digest solutions were diluted to $25 \mathrm{~mL}$ with ultrapure $(18 \Omega)$ water and stored at $4^{\circ} \mathrm{C}$.

Concentrations of $\mathrm{Ca}, \mathrm{Mg}, \mathrm{K}, \mathrm{Zn}, \mathrm{Pb}, \mathrm{Cd}, \mathrm{Cu}, \mathrm{Ni}$, and $\mathrm{Mn}$ in digest solutions were measured by ICP-OES using standard methods modified from Zarcinas et al. (1987). We included as standard reference materials peach leaves (NIST 1547) and either olive leaves (BCR 062) or citrus leaves (NIST 1572), as well as a reagent blank, to confirm the quality of each digest. We further verified ICP-OES measurements by including standard solutions of known concentrations in each run. We used a similar method to measure metal concentrations in soils collected at the beginning of the experiment. Soils were sieved to $2 \mathrm{~mm}$, airdried, then ashed, digested, and analyzed by ICP-OES as above, a protocol modified from EPA method 3050B.

\section{Testing Elemental Allelopathy}

We performed a series of experiments to test three fundamental components of the mechanism of elemental allelopathy. To determine the extent that gray birch trees accumulate heavy metals in their leaves relative to their neighbors, a criterion for elemental allelopathy, we compared foliar metal concentrations in birch and the planted grasses. To test whether birch trees were associated with local increases in soil metal concentrations, we measured topsoil metal concentrations as a function of distance from gray birch trees in the field. Finally, we conducted a greenhouse experiment to evaluate phytotoxicity of gray birch leaf litter.

We collected leaves from 12 gray birch trees and 4-8 individuals each of nine planted grass species in July 2014 and measured metal and nutrient concentrations for each individual plant by ICP-OES as described above. To determine potential effects of birch on soil chemistry, in August 2013, we sampled soil from the top $\sim 10 \mathrm{~cm}$ at points located $0,50,100$, and $200 \mathrm{~cm}$ from the stems of 18 gray birch trees located throughout the Palmerton site. We selected from among larger trees $(\sim 5-10$ years old, $2-$ $4 \mathrm{~m}$ tall, canopy radius $<2 \mathrm{~m}$ ), and established our soil collection points along a cardinal direction chosen randomly for each tree such that the focal tree was the closest gray birch tree to each collection point. We then measured soil metal concentrations and organic matter content as described above.

We tested the phytotoxicity of metal-contaminated gray birch leaves from the site using a greenhouse experiment. We grew seedlings of autumn bent grass (Agrostis perennans; Poaceae), the forb white snakeroot (Ageratina altissima; Asteraceae), black oak, and sugar maple individually in pots of contaminated soil collected from the site, into which we manually mixed dried, crushed gray birch leaves, with three levels of leaf treatments: collected from inside the contaminated site, collected at nearby uncontaminated sites, or no leaves. To confirm differences in elemental concentration between contaminated and uncontaminated leaves, we measured metal and nutrient concentrations in 40 samples of each using ICP-OES. We collected seeds of autumn bent grass and white snakeroot from the Palmerton site in Fall 2013, and germinated them in autoclave-sterilized sand in Spring 2014 before transplanting into experimental pots. These two understory species colonized the site naturally and are abundant there, so they evidently have some degree of heavy metal tolerance. Seedlings of black oak and sugar maple came from the same batch as those used for the field experiment, and were transplanted into experimental pots upon arrival. We replaced any seedlings that died within the first week of the experiment.

Soil for the greenhouse experiment came from 10 locations within the grassland-dominated area in the Palmerton site, with 
each location supplying soil for one replicate of every speciestreatment combination. Soils were mixed with sand in a $6: 1$ soil:sand ratio to improve drainage. For each species, we planted similarly sized seedlings in the different leaf litter treatments to avoid confounding experimental treatments with initial size. We planted autumn bent and white snakeroot in $150 \mathrm{~mL}$ pots filled with soil mixed with $3 \mathrm{~g}$ of crushed leaves, and black oak and sugar maple in $550 \mathrm{~mL}$ pots with soil mixed with $4 \mathrm{~g}$ of crushed leaves. Leaf amounts were chosen to strike a balance between similar leaf masses and similar leaf:soil ratios in each pot. Pots were randomized with respect to replicates and treatments upon planting and repeatedly throughout the experiment. Because of differences in life history, we grew autumn bent for 11 weeks, white snakeroot for 21 weeks, and black oak and sugar maple for 23 weeks. To assess performance at harvest, we measured for autumn bent grass: height, number of tillers, and aboveground and belowground biomass; for white snakeroot: height, number of leaves, and aboveground and belowground biomass; for black oak and sugar maple: height, the length of apical and lateral branches from the current growing season in the greenhouse and past growing season in the nursery, number of leaves, and biomass of leaves, woody aboveground tissue, and fine and coarse roots based on a $1 \mathrm{~mm}$ diameter cutoff. For five replicates of each species, we also measured leaf metal and nutrient concentrations by ICP-OES.

\section{Statistical Analysis}

For the field experiment, we used linear models to test for effects of vegetation type (birch vs. grass) and aboveground competition (cleared vs. intact) on soil metal and nutrient concentrations, soil moisture, soil temperature, and light availability, as well as the growth, metal and nutrient uptake, and fungal root colonization parameters, analyzing black oak and sugar maple seedlings separately. For most parameters, we had multiple measurements per plot and thus included plot as a random effect in the models. Models depended on data distributions: ANOVAs for continuous variables such as branch lengths and biomass, which were $\log _{10^{-}}$ transformed as necessary to improve normality, MANOVAs for multivariate metal concentration profiles, and generalized linear models (GLMs) for leaf number (poisson) and root mycorrhizal colonization (binomial).

We tested for effects of vegetation type, aboveground competition, and their interaction on several metrics of community composition: birch and grass cover, and the cover, Shannon diversity (ANOVA) and species richness (GLM) of other colonizing species. We used chi-squared tests to test for associations between herbivory levels and experimental treatments for black oak and sugar maple separately. We constructed three contingency tables, one to isolate vegetation type, another for clearing, and another combining the two treatments. We used three levels of herbivory for black oak but because insect herbivory on sugar maple was generally low, we re-coded sugar maple leaf herbivory as presence/absence to avoid violating assumptions of the chi-squared test.

To test for differences between birch and grass in metal and nutrient concentrations, we used two-tailed $t$-tests to account for the possibility that birches may have greater concentrations of some metals and grasses may have greater concentrations of others. We adjusted significance thresholds using the DunnŠidák correction for multiple comparisons. To determine whether soil concentrations of each metal or nutrient varied significantly with distance from a focal gray birch tree, we used linear regression, again correcting for multiple tests. Metal and nutrient concentration data was $\log _{10}$-transformed to improve normality. To account for potential differences in background metal and nutrient concentrations under the sampled trees, we repeated this analysis with each concentration expressed as the change in concentration from the base of the trunk.

We used MANOVA to investigate the effects of grass and birch on soil metal concentrations at the beginning of the experiment. To investigate the effects of soil metal concentration profiles measured at the beginning of the experiment on plant biomass at harvest, we used principal components analysis (PCA) to produce axes that captured the majority of the variation in our soil chemistry data and then regressed plant biomass against these axes. Finally, we used correlation matrices to investigate the relationships between leaf and soil metal and nutrient concentrations.

In the greenhouse experiment, we used ANCOVA to test for an effect of litter treatment (contaminated, uncontaminated, or none) on each measure of plant performance and metal and nutrient concentration. We included depth to soil surface as a covariate in all models because soil settled in the pots to different degrees during the experiment, creating differences in the available amount of soil, and potentially nutrient availability. We repeated analyses excluding the no litter treatment to be sure to detect differences contributed by contaminated leaves vs. uncontaminated leaves, if they were present.

\section{RESULTS}

\section{Gray Birch Effects on Soil Characteristics and Plant Community Structure}

Compared to the grasses, gray birch had approximately 10-fold greater leaf concentrations of the pollutants $\mathrm{Zn}$ and $\mathrm{Cd}(P<$ 0.001), but not $\mathrm{Pb}$ (Figure 1). Our spring 2014 measurements, before clearing and planting, showed that birch plots, excluding birch itself, had lower vegetative cover than grass plots $(P$ $<0.001$, Figure 2A). However, species that colonized the site independently, excluding birch and the planted grasses, had marginally greater species richness $(P<0.1$, Figure 2B) and greater Shannon diversity $(P<0.05)$ in birch plots. Plots designated to be cleared did not significantly differ in cover, richness, or diversity from plots designated to be left intact.

Abiotic conditions in the plots differed with initial vegetation type and clearing of aboveground competition. Soil organic matter content, measured at the beginning of the field experiment, was marginally higher in grass plots than birch plots, but soil heavy metal and nutrient concentrations did not differ (Table 1). We observed marginal main treatment effects on soil moisture measured during the experiment; moisture was greater in grass plots $(P<0.1$; Table 2$)$ and in cleared plots $(P<$ 0.1 , with no significant interaction. Soil temperature was greater 


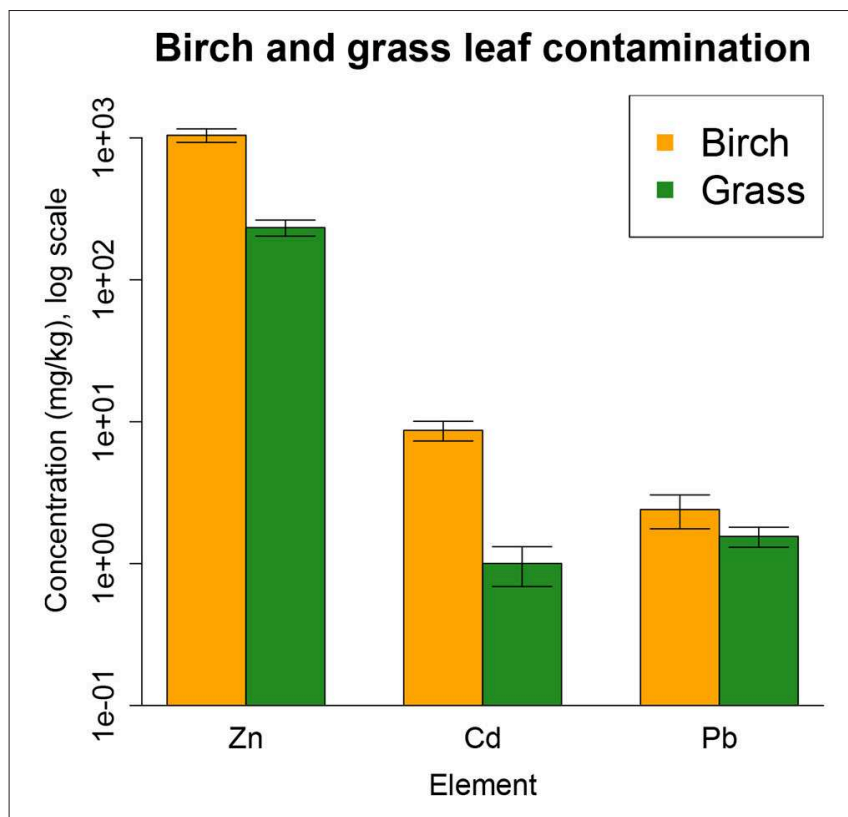

FIGURE 1 | Concentrations of the contaminants $\mathrm{Zn}, \mathrm{Cd}$, and $\mathrm{Pb}$ in leaves of gray birch (orange bars) and the planted grasses (green bars) in the Palmerton site (average $\pm \mathrm{SE}$ ). Grasses and birch differ in $\mathrm{Zn}$ and $\mathrm{Cd}(P<0.001)$ but not in $\mathrm{Pb}$. The $\mathrm{y}$-axis is on a log scale for readability. Error bars are $\pm 1 \mathrm{SE}$.

in cleared plots $(P<0.05)$, and leaf area index, a proxy for aboveground competition or shading, was greater in intact plots $(P<0.001$; Table 2). Leaf area index was $>0$ in cleared plots because of the experimental tree seedlings and partial regrowth of vegetation between clippings. Neither soil temperature nor leaf area index differed between grass and birch plots.

\section{Gray Birch and Aboveground Competition Impacts on Tree Species Establishment, Fungal Root Colonization, and Herbivory}

Black oak germination approximately tripled with clearing in grass plots but decreased slightly with clearing in birch plots, producing a significant vegetation type $\mathrm{x}$ clearing interaction $(P<0.05$; Figure 3A) but no main effect of either. There was no main effect of vegetation type or clearing. Sugar maple seed germination did not differ between experimental treatments (Figure 3B).

As seedlings, neither species performed differently in plots dominated by birch vs. grasses, as a main effect, based on any measure of performance. Growth of black oak responded to vegetation clearing, where seedlings in cleared plots had significantly more leaves $(P<0.05$, Figure 3C) and lateral branches, greater lateral branch length (Table A1), and marginally greater total biomass $(P<0.1$, Figure 3E). For black oak, fine root biomass responded to a significant vegetation type $\mathrm{x}$ clearing interaction where clearing had little effect in birch plots but more than doubled fine root biomass in grass plots $(P<0.05$, Figure 3G). Sugar maple seedlings showed no significant effects of experimental treatments or their interactions
A Vegetative cover

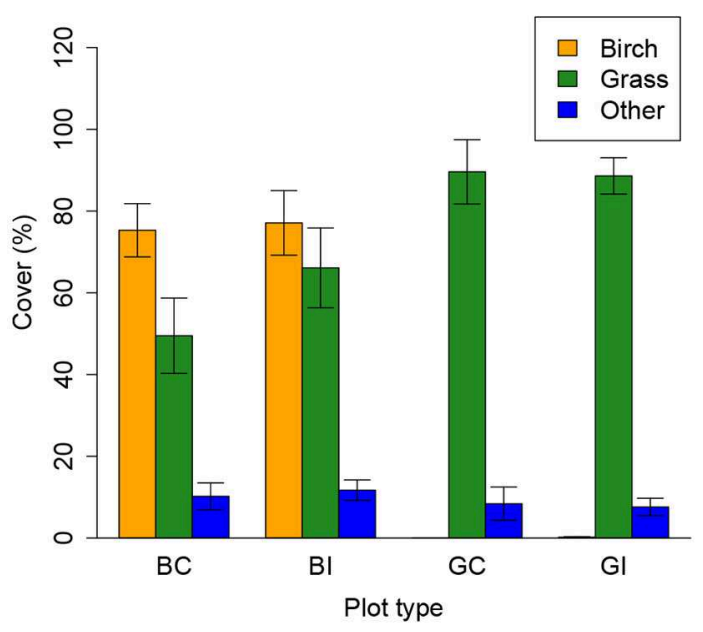

B Colonizing species richness

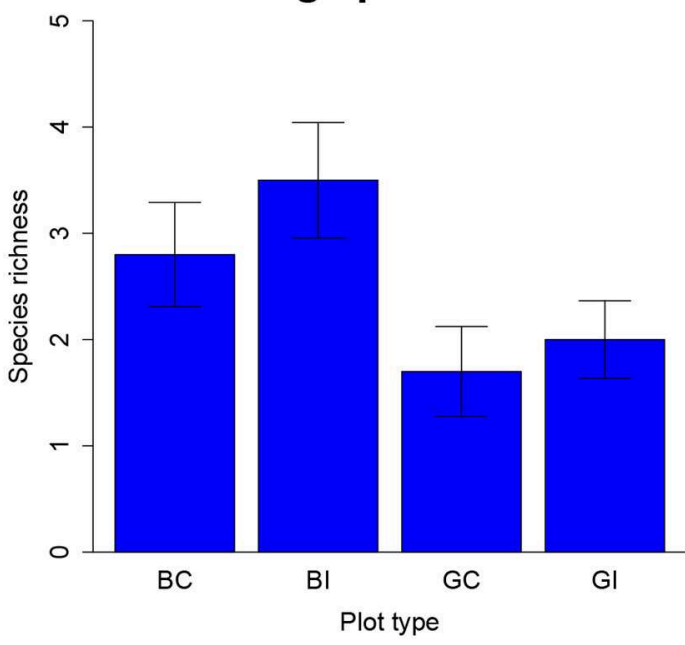

FIGURE 2 | Birch and grass effects on neighboring plant communities assessed in experimental field plots before beginning the experiment in May 2014. (A) Cover of gray birch (orange bars), grasses (green bars), and all other colonizing species (blue bars). (B) Species richness of colonizing species excluding birch and grasses. Plot treatments are abbreviated as follows: Birch, B; Grass, G; Cleared, C; Intact, I. Error bars are \pm 1SE. Gray birch is excluded from all plant community data and analyses except gray birch cover. In the "grass" category, we include the planted $\mathrm{C}_{4}$ grasses Andropogon gerardii, Eragrostis trichodes, Panicum amarum, Panicum virgatum, Sorghastrum nutans, Schizachyrium scoparium, and Tripsacum dactyloides, the planted $\mathrm{C}_{3}$ grasses Dichanthelium clandestinum and Elymus canadensis, and the $\mathrm{C}_{3}$ grass Agrostis perennans, which was not planted but occurred in the site before revegetation and grew abundantly in some plots. Grasses were treated as a single group because they were the dominant species in the grass plots at the beginning of the experiment and most species could not reliably be distinguished when this early-season census was conducted. All species other than gray birch or the above grasses were considered other colonizing species.

on any of the growth parameters we measured (Figures 3D,F,H). Seedling height increments from the beginning to the end of the experiment were often negative for both species, but especially 
TABLE 1 | Initial plant community structure (A) and soil chemistry (B) of birch and grass plots before clearing treatment.

\begin{tabular}{|c|c|c|c|c|}
\hline & & Birch & Grass & Difference \\
\hline \multicolumn{5}{|l|}{ (A) } \\
\hline & Birch cover (\%) & $76.2 \pm 5.0$ & $0.10 \pm 0.07$ & $\mathrm{~B}>\mathrm{G}^{\star \star \star}$ \\
\hline & Grass cover (\%) & $57.8 \pm 6.8$ & $89.1 \pm 4.4$ & $G>B^{\star \star \star}$ \\
\hline \multirow[t]{3}{*}{ Colonizing species } & Cover (\%) & $11.0 \pm 2.0$ & $8.0 \pm 2.2$ & NS \\
\hline & $\begin{array}{l}\text { Species } \\
\text { richness }\end{array}$ & $3.2 \pm 0.36$ & $1.9 \pm 0.27$ & $\mathrm{~B}>\mathrm{G}()$. \\
\hline & $\begin{array}{l}\text { Shannon } \\
\text { diversity }\end{array}$ & $0.82 \pm 0.12$ & $0.49 \pm 0.10$ & $B>G^{*}$ \\
\hline \multicolumn{5}{|l|}{ (B) } \\
\hline & $\begin{array}{l}\text { Organic matter } \\
(\% \text { LOI) }\end{array}$ & $25.9 \pm 3.3$ & $34.6 \pm 3.4$ & NS \\
\hline \multirow[t]{3}{*}{ Base cations } & $\mathrm{Ca}(\mathrm{mg} / \mathrm{kg})$ & $1441 \pm 344$ & $1884 \pm 571$ & NS \\
\hline & $\mathrm{Mg}(\mathrm{mg} / \mathrm{kg})$ & $10624 \pm 3776$ & $9516 \pm 3311$ & NS \\
\hline & K (mg/kg) & $1840 \pm 96$ & $1876 \pm 96$ & NS \\
\hline \multirow[t]{3}{*}{ Contaminants } & $\mathrm{Zn}(\mathrm{mg} / \mathrm{kg})$ & $7007 \pm 1197$ & $8417 \pm 1270$ & NS \\
\hline & $\mathrm{Pb}(\mathrm{mg} / \mathrm{kg})$ & $683 \pm 136$ & $1006 \pm 187$ & NS \\
\hline & $\mathrm{Cd}(\mathrm{mg} / \mathrm{kg})$ & $79.8 \pm 17.2$ & $110.3 \pm 21.1$ & NS \\
\hline \multirow[t]{3}{*}{ Other heavy metals } & $\mathrm{Ni}(\mathrm{mg} / \mathrm{kg})$ & $13.0 \pm 1.7$ & $15.8 \pm 2.0$ & NS \\
\hline & $\mathrm{Cu}(\mathrm{mg} / \mathrm{kg})$ & $128 \pm 25$ & $143 \pm 21$ & NS \\
\hline & $\mathrm{Mn}(\mathrm{mg} / \mathrm{kg})$ & $4934 \pm 878$ & $6281 \pm 1033$ & NS \\
\hline
\end{tabular}

Statistical significance of effects is denoted in the Difference column as follows: B birch, G grass, $C$ cleared, I intact, (.) $P<0.1,{ }^{*} P<0.05$, ${ }^{* * *} P<0.001$. Values are average \pm 1 SE.

TABLE 2 | Effects of birch, grasses, and clearing of aboveground vegetation on soil moisture, temperature, and leaf area index (a proxy for aboveground competition) in experimental field plots.

\begin{tabular}{lccc}
\hline Plot type & $\begin{array}{c}\text { Soil } \\
\text { moisture }(\% \\
\mathbf{v} / \mathbf{v})\end{array}$ & $\begin{array}{c}\text { Soil } \\
\text { temperature } \\
\left({ }^{\circ} \mathbf{C}\right)\end{array}$ & $\begin{array}{c}\text { Leaf area } \\
\text { index }\end{array}$ \\
\hline $\mathrm{BC}$ & $7.10 \pm 1.59$ & $32.5 \pm 0.60$ & $0.313 \pm 0.045$ \\
$\mathrm{GC}$ & $10.68 \pm 1.48$ & $30.8 \pm 0.56$ & $0.383 \pm 0.239$ \\
$\mathrm{Bl}$ & $3.79 \pm 0.79$ & $29.9 \pm 0.47$ & $1.546 \pm 0.232$ \\
$\mathrm{Gl}$ & $7.11 \pm 1.28$ & $29.8 \pm 0.49$ & $0.954 \pm 0.109$ \\
Difference & $\mathrm{G}>\mathrm{B}(.) \mathrm{C}>\mathrm{l}()$. & $\mathrm{C}>1^{*}$ & $\mathrm{I}>\mathrm{C}^{\star * *}$ \\
\hline
\end{tabular}

Plot treatments are abbreviated as follows: Birch, B; Grass, G; Cleared, C; Intact, I. Statistical significance of effects is denoted in the Difference row as follows: (.) $P<0.1$, ${ }^{\star} P<0.05,{ }^{\star \star \star} P<0.001$.

so for sugar maple, presumably due to both low growth and herbivory. Height increments did not respond to experimental treatments in either species (Figures 3I,J).

Vegetation type did affect root colonization by fungi. For black oak, ECM colonization was marginally greater in birch plots than grass plots $(P<0.1$, Figure 4A), and explained significant variation in aboveground, belowground, and total seedling biomass $(P<0.001$, Figure $4 B$ ). For sugar maple, AMF colonization did not respond to vegetation or clearing as main
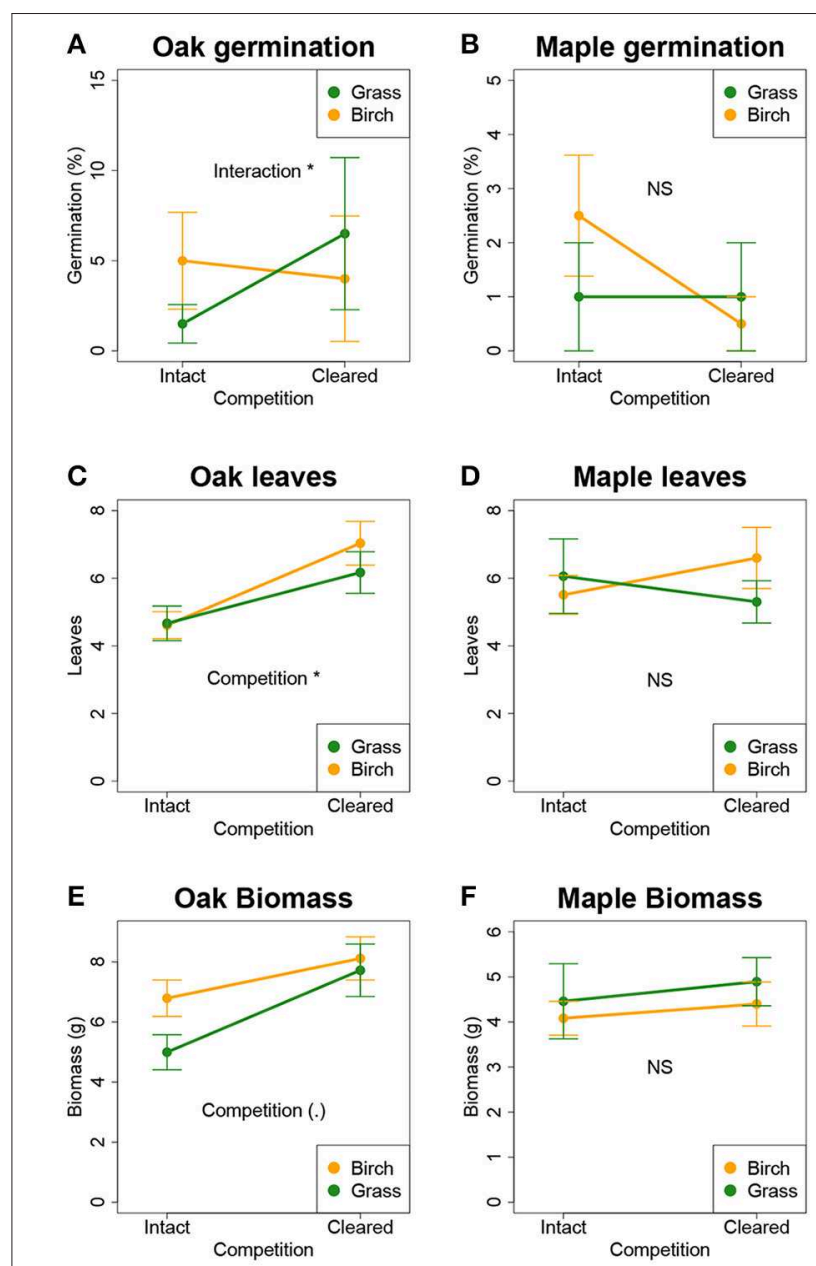

G Oak fine root biomass
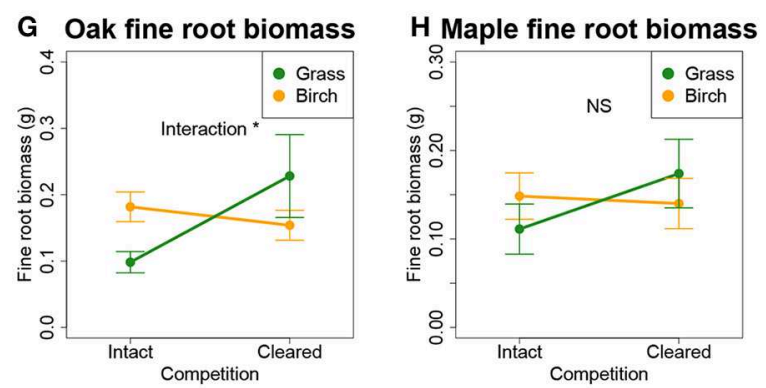

I Oak Height Increment
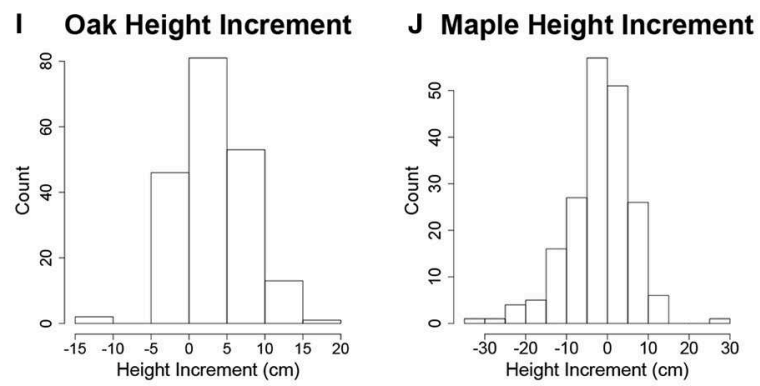

FIGURE 3 | Germination, leaf number, total biomass, and fine root biomass of black oak and sugar maple seedlings (A-H) in the field experiment, shown as (Continued) 
FIGURE 3 | a function of the vegetation type into which they were planted and whether aboveground competition was eliminated by clearing. Distribution of changes in height from planting until harvest $\mathbf{( I , J ) ~ c o m b i n e s ~ s e e d l i n g s ~ i n ~ a l l ~ f o u r ~}$ vegetation type ${ }^{*} c l e a r i n g$ treatments. Significance codes: (.) $P<0.1$; ${ }^{\star} P<0.05$; NS not significant. Error bars are \pm 1 SE.
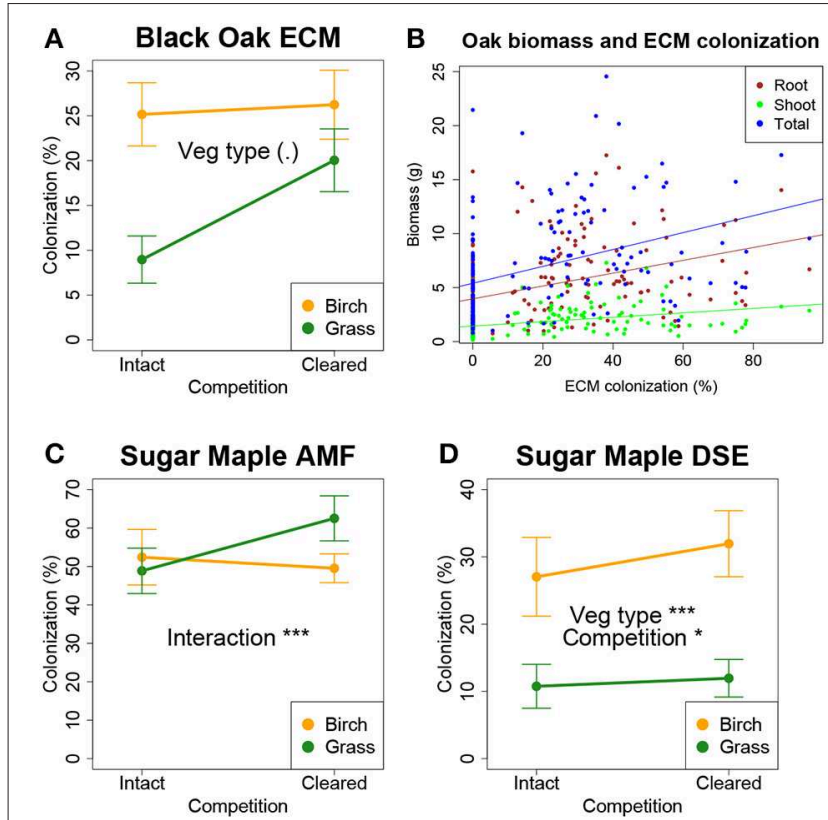

FIGURE 4 | Fungal root colonization for seedlings in the field experiment. (A) Percent colonization of black oak by ECM by vegetation type and clearing treatment. (B) Percent ECM colonization explains variation in aboveground, belowground, and total biomass $(P<0.001)$. Percent colonization of sugar maple roots by AMF (C) and DSE, dark staining fungal endophytes (D). Significance: (.) $P<0.1 ;{ }^{\star} P<0.05 ;{ }^{\star \star \star} P<0.001$. Error bars are \pm 1 SE.

effects, but there was a vegetation type $\mathrm{x}$ clearing interaction $(P$ $<0.001)$ reflecting greater colonization in cleared grass plots than in other treatment combinations (Figure 4C). Also for sugar maple, DSE colonization was greater in birch plots than in grass plots $(P<0.001$, Figure 4D), and greater in cleared plots than intact plots $(P<0.05$, Figure 4D), with no significant interaction. Neither AMF nor DSE root colonization explained variation in sugar maple biomass.

Insect herbivory on black oak leaves was greater in birch plots compared to grass plots $(P<0.05$, Figure 5A). For sugar maple, insect leaf herbivory did not vary with vegetation type or clearing (Figure 5B).

\section{Gray Birch and Aboveground Competition Effects on Seedling and Soil Metal Concentrations}

Leaf metal and nutrient concentrations in seedlings responded to aboveground competition but not vegetation type. MANOVA showed a significant effect of aboveground competition on black oak leaf metal profiles $(P<0.001)$ and a marginal effect of aboveground competition on sugar maple leaf metal profiles $(P$ $<0.1$ ), but no effect of vegetation type in either case. Univariate analyses of black oak and sugar maple leaf metal concentrations revealed that black oak leaves had marginally higher $\mathrm{Al}, \mathrm{K}$, and $\mathrm{Cu}$ in cleared plots than intact plots $(P<0.1)$ and marginally higher leaf $\mathrm{Cu}$ in birch plots than in grass plots $(P<0.1)$. Sugar maple leaves had marginally greater $\mathrm{Zn}$ and $\mathrm{Pb}(P<0.1)$ and significantly greater $\mathrm{Cd}(P<0.05)$ in cleared plots than intact plots (Table A2). However, none of these univariate results was statistically significant after correcting for multiple comparisons.

Principal components analysis of soil metal and nutrient concentration profiles captured about $90 \%$ of the variation in the first three axes. Biplot analysis showed that the first axis was negatively related to the pollutants, other heavy metals, and organic matter. The second axis was positively related to $\mathrm{Ca}$ and $\mathrm{Mg}$ and negatively related to $\mathrm{K}$, and the third axis was negatively related to K (Figure 6). Regression of plant biomass parameters showed that black oak root, shoot, and total biomass were all negatively related to axis $3(P<0.001)$, and shoot biomass was also positively related to axis $2(P<0.05)$. Because the negative relationship between oak biomass and axis 3 suggests a positive relationship between biomass and soil $\mathrm{K}$, but the positive relationship between oak shoot biomass and axis 2 suggests the opposite, we performed univariate regressions to further investigate the relationships between oak biomass and soil $\mathrm{K}$. We found that soil $\mathrm{K}$ was positively related to black oak aboveground, belowground, and total biomass $(P<0.001)$. For sugar maple, root and shoot biomass were each positively related to axes 1 and $2(P<0.05)$. Total sugar maple biomass was positively related to axis $1(P<0.05)$ but only marginally positively related to axis 2 $(P<0.1)$.

Correlations between soil and plant metal concentrations were weak but mostly positive. However, contrary to expectations, the foliar concentration of a given element was seldom as highly correlated with the soil concentration of that same element as it was with soil concentrations of other elements (Figures A1A,B). For black oak, the stronger relationships included the following: foliar $\mathrm{Pb}$ and $\mathrm{Cd}$ were negatively related to soil $\mathrm{Ca}$ and $\mathrm{Mg}$, and foliar $\mathrm{Zn}$ was positively related with soil $\mathrm{Zn}, \mathrm{Cd}$, and $\mathrm{Ni}$ (Figure A1A). For sugar maple, soil $\mathrm{Ca}$ and $\mathrm{Mg}$ were strongly positively related to foliar $\mathrm{Mg}$ and negatively related to the rest of the elements measured. Foliar $\mathrm{Pb}$ and $\mathrm{Cd}$ were negatively related to soil $\mathrm{Ca}, \mathrm{Mg}$, and LOI. Foliar Zn, LOI, and to a lesser extent Cd, were negatively related to soil $\mathrm{Ca}$ and $\mathrm{Mg}$ and weakly positively related to soil $\mathrm{Zn}, \mathrm{Pb}, \mathrm{Cd}, \mathrm{Mn}$, and $\mathrm{Ni}$ (Figure A1B).

\section{Elemental Allelopathy}

Despite large differences in the $\mathrm{Zn}$ and Cd concentrations of birch and grass leaves (Figure 1), we observed no signature of heavy metal enrichment around birch trees. Levels of soil contaminants around birch trees were highly variable, and there were no significant trends in concentrations of soil organic matter, base cations, or heavy metals, as a function of distance from stem, whether we analyzed absolute concentrations or changes in concentration with distance from stem (Figure A2).

For our greenhouse experiment, we confirmed that gray birch leaves collected inside the Palmerton site had significantly higher 

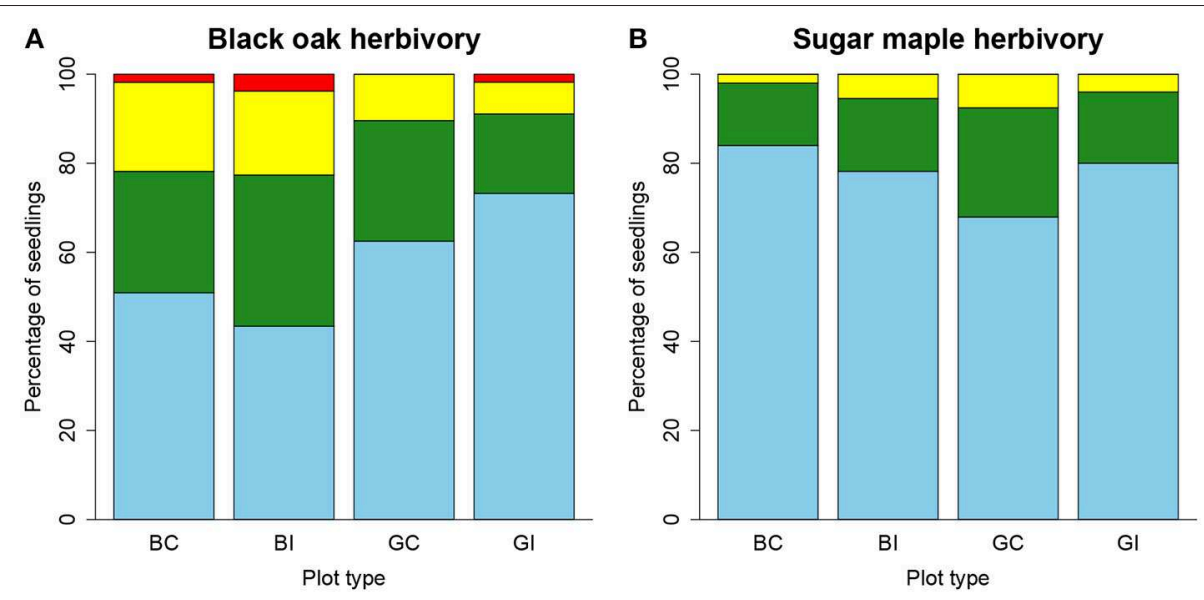

FIGURE 5 | Percentage of black oak (A) and sugar maple (B) seedlings experiencing different classes of insect leaf herbivory while grown in birch (B) or grass (G) dominated plots in the field with aboveground competition cleared (C) or left intact (I). Classes of leaf herbivory are defined and color-coded as follows by the amount of leaf area apparently missing: None, blue, <5\%; Minimal, green, 5-20\%; Moderate, yellow, 20-50\%; Severe, red, >50\%.

concentrations of the pollutants $\mathrm{Zn}, \mathrm{Pb}$, and $\mathrm{Cd}$ than gray birch leaves collected outside the site (all $P<0.001$, Figure 7). After correcting for multiple comparisons, contaminated and uncontaminated gray birch leaves did not differ in any of the other chemical characteristics we measured, including organic matter, the base cations $\mathrm{Ca}, \mathrm{K}$, and $\mathrm{Mg}$, and the heavy metals $\mathrm{Cu}$ and $\mathrm{Ni}$.

Growth and elemental uptake responses by our four target species exposed to birch litter treatments in the greenhouse were species-specific and often minimal. Moreover, none showed predicted evidence of elemental allelopathy, which would be reduced growth and/or greater foliar $\mathrm{Zn}, \mathrm{Pb}$, or $\mathrm{Cd}$ concentrations when grown with contaminated litter. Black oak grew taller and had more fine root biomass with contaminated gray birch leaf litter than with uncontaminated litter or no litter (Figures 8A,B), but aboveground and total biomass did not respond to the litter treatments. Autumn bent grass grew more in the absence of birch leaves, having about twice as much aboveground biomass, belowground biomass, and tiller number in pots without litter added (Figure 8C) but showed no response to litter contamination. Growth of white snakeroot and sugar maple also did not respond to the litter treatments. No species showed an effect of litter treatment on their leaf contaminant concentrations.

\section{DISCUSSION}

As succession proceeds in this remediated grassland, gray birch is more likely to engage in PSF by influencing the types of fungal root symbionts than by performing elemental allelopathy, despite gray birch's elevated foliar levels of $\mathrm{Zn}$ and $\mathrm{Cd}$. Black oak performance was more responsive to soils conditioned by gray birch vs. grasses than was sugar maple, demonstrating species-specific consequences, and some soil-mediated effects only occurred in the absence of the neighboring plant canopy, indicating an interaction between aboveground competition and soil factors. Herbivory by deer may also have obscured PSF effects on seedling performance. We suggest that gray birch could influence succession broadly by lowering soil moisture, soil organic matter, and cover of light-demanding species, increasing plant species diversity, and changing soil microbial communities, compared to grasses.

Based on our findings, gray birch should help steer succession to other woody species that likewise associate with ECM. Gray birch apparently fosters a shift in mycorrhizal communities, from an AMF-dominated community under grasses to a more mixed community of AMF, ECM, and DSE. Although DSE are not formally considered mycorrhizal fungi, they can have very similar functions (Jumpponen, 2001). Shifts between AMF and ECM have been associated with succession and other plant community shifts before (Treseder et al., 2004, AMF to ECM; Williams et al., 2013, ECM to AMF), and have been shown to facilitate recruitment or growth of ECM-reliant woody species (Pringle et al., 2009). It is possible that different soil microbes under birch and grasses, including the fungi we analyzed, also contributed to greater black oak seed germination in cleared grass plots (e.g., Maighal et al., 2016; Varga and Kytöviita, 2016). Similarly, AMF colonization in sugar maples was greater in plots conditioned by AMF-dependent grasses as we predicted, but only when aboveground competition was removed and with no linkage to seedling biomass. Perhaps sugar maple seedlings become more favorable fungal hosts because aboveground clearing reduces photosynthate production in surrounding grass-dominated vegetation, making the maples relatively more desirable fungal hosts.

Any potential effects of fungal root colonization or experimental treatments on sugar maple might have been hidden because of this species' overall poor growth. Sugar maple may be less tolerant than black oak of heavy metal soils, or may have experienced too much herbivory by deer, despite our efforts to shield seedlings from vertebrate herbivores. Herbivory can mask effects of other ecological processes, especially if herbivores 

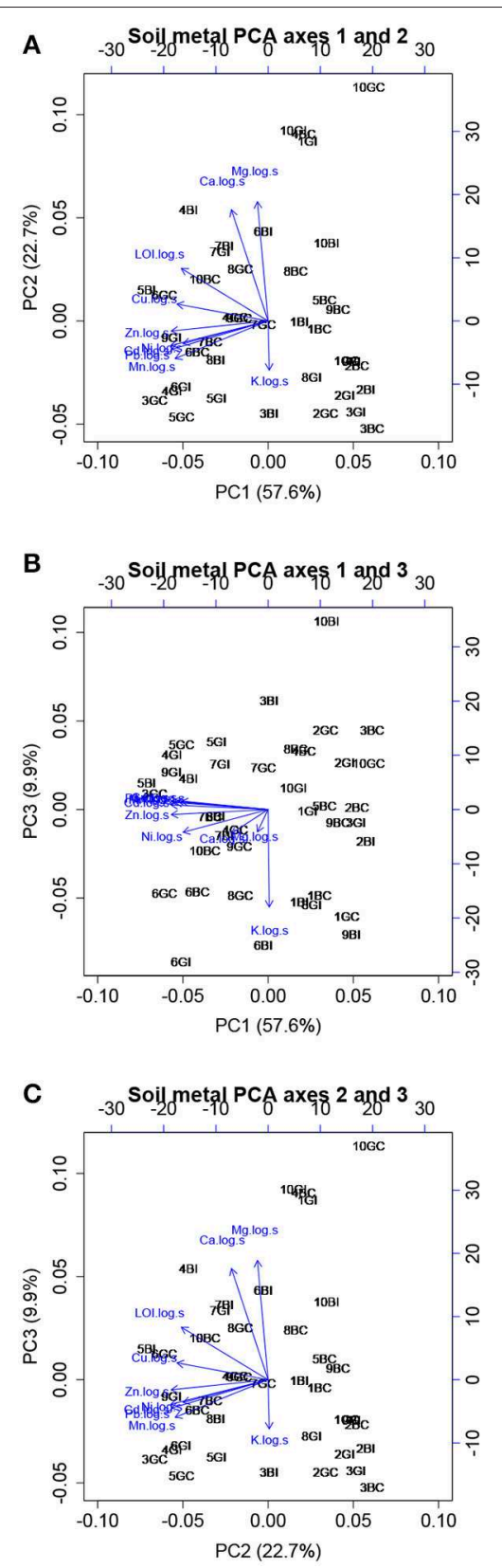

FIGURE 6 | Principal components analysis of log-transformed soil chemistry data, including concentrations of soil organic matter, the nutrients $\mathrm{Ca}, \mathrm{Mg}$, and $\mathrm{K}$, the contaminants $\mathrm{Zn}, \mathrm{Pb}$, and $\mathrm{Cd}$, and the heavy metals $\mathrm{Cu}, \mathrm{Ni}$, and $\mathrm{Mn}$ not thought to be enriched in the site. Axes 1 and 2 (A), 1 and $3 \mathbf{( B )}$, and 2 and 3 (C). Points show the location of each plot in the ordination space, and arrows are biplots showing contributions of each chemical concentration to the ordination space.

preferentially attack larger, healthier seedlings (Price, 1991; Blaisdell et al., 2015), or otherwise interact with PSF in affecting plant performance (Bennett and Klironomos, 2019; Heinze et al., 2019).

Aboveground competition also proved consequential for black oak performance, both as a main effect on leaf number and

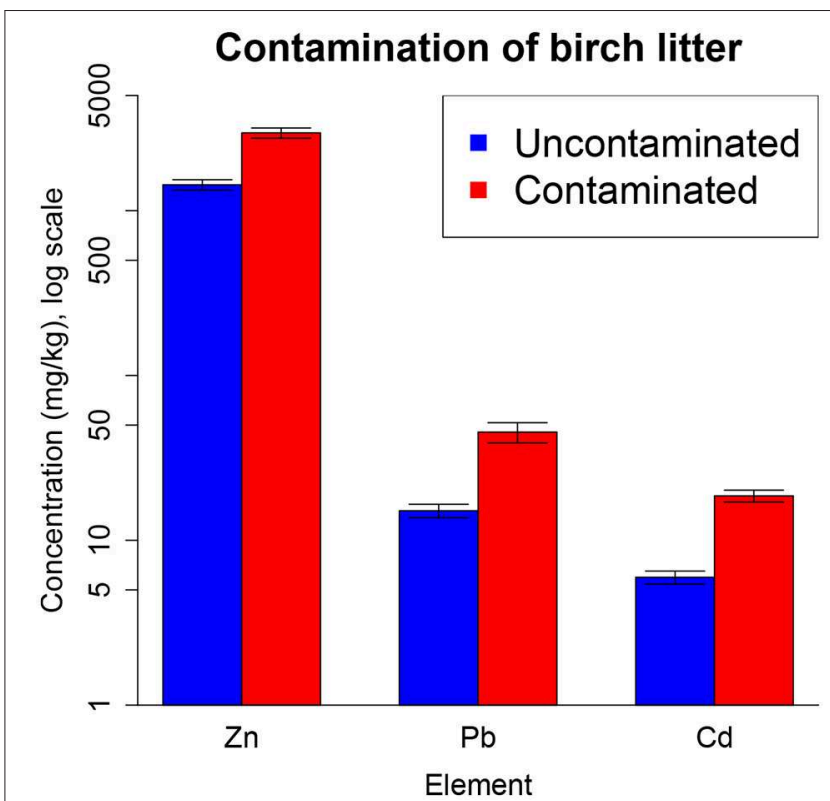

FIGURE 7 | Concentrations of the heavy metal contaminants $\mathrm{Zn}, \mathrm{Pb}$, and $\mathrm{Cd}$ in gray birch leaves collected inside (red) and outside (blue) of the contaminated site and used for the greenhouse experiment. Birch leaves from inside the contaminated site had significantly higher concentrations of all three contaminants $(P<0.001, N=40)$. Error bars are \pm 1 SE.

seedling biomass and as an interaction with vegetation type affecting seed germination and fine root biomass. The expression of soil effects on black oak germination and fine root biomass only in the absence of aboveground competition is consistent with findings of several other studies, where competition masks or reduces effects of PSF (Casper and Castelli, 2007; Bezemer et al., 2018; Lekberg et al., 2018; Xue et al., 2018). Our measures of soil temperature, soil moisture, and LAI confirmed that shading by uncleared vegetation impacted the abiotic environment.

The greater insect herbivory on black oak seedlings growing in soils conditioned by gray birch, compared to soils conditioned by grasses, has multiple possible explanations. Soil characteristics under grasses and gray birch, including differences in mycorrhizae, might have differentially influenced herbivore activity (Koricheva et al., 2009) by altering leaf properties such as nutritional quality or defense chemistry (Kostenko et al., 2012; Kos et al., 2015; Wang et al., 2015), although in this case herbivory was greater in gray birch plots where ECM colonization was also greater. Plant neighbor identity has been shown to influence plant herbivory defense strategies as well (Broz et al., 2010). Neighboring gray birch might also have elevated herbivory on black oak through association susceptibility (Barbosa et al., 2009; Kim, 2017), in which gray birch served as an herbivore attractant or black oak was a preferred, alternate food choice.

We found no strong evidence in either the field experiment or the greenhouse experiment that gray birch engages in elemental allelopathy. Soil concentrations of $\mathrm{Zn}$ and $\mathrm{Cd}$ did not decrease with distance from gray birch stems as would be expected if gray birch litter locally enriches these soil contaminants (Jaffe 


\section{A Autumn bent grass biomass}
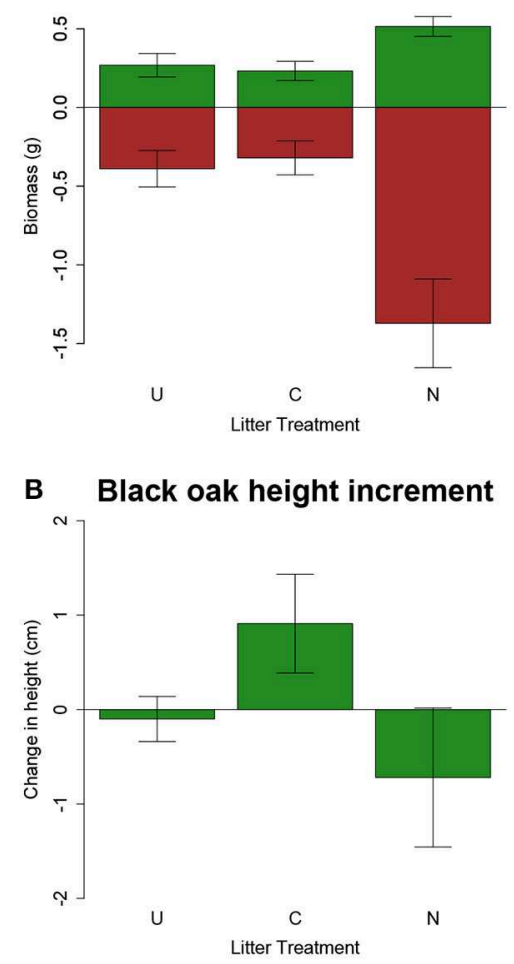

C Black oak fine root biomass

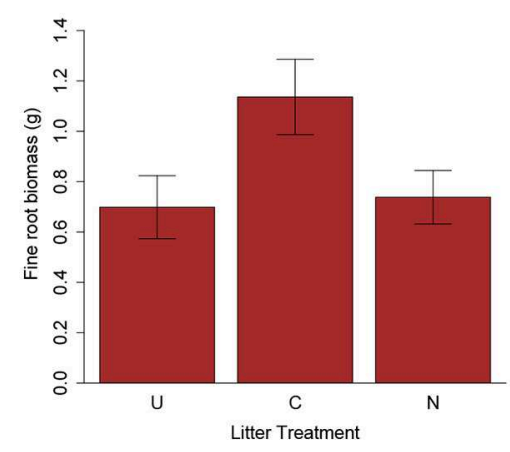

FIGURE 8 | Effects of birch litter treatments on plant growth in the greenhouse experiment, showing only results that differed between contaminated (C), uncontaminated (U), and no (N) litter treatments. (A) Biomass of autumn bent grass: bars above the $\mathrm{x}$-axis represent aboveground biomass, and bars below the $\mathrm{x}$-axis belowground biomass. (B) Change in height from planting until harvest and (C) fine root biomass in black oak seedlings. Green bars represent aboveground growth and brown bars represent belowground growth. Error bars are \pm 1 SE.

et al., 2017). It is possible that elemental allelopathy by gray birch impacted black oak seed germination and fine root production in the field, since both were greater in soils conditioned by grasses in the absence of aboveground competition, but it seems more likely that soil metal concentrations are sufficiently high and variable as to overpower any signal of birch-mediated metal movement. Furthermore, in the greenhouse experiment, contaminated birch litter actually increased oak height and fine root biomass, suggesting a positive effect on oak performance. Leaching of contaminants from leaf litter is likely (MaunouryDanger et al., 2018). $\mathrm{Zn}$ has been shown to increase fine root growth in some concentrations (Feigl et al., 2019), but we cannot explain why contaminated litter increased black oak seedling height. The negative response of autumn bent grass to any birch litter, whether contaminated or not, could be due to the high phenolic content of birch leaves (Keinänen et al., 1999) and might indicate that gray birch, regardless of its metal uptake, could have negative consequences for some early successional species.

The ability to engage in elemental allelopathy has been offered as one explanation for the evolution of metal hyperaccumulation in plants (Rascio and Navari-Izzo, 2011), but examples in the literature are mostly inconclusive, unable to distinguish between a species contributing to locally elevated contamination and its preferential growth or establishment in pockets of high soil metal concentration (Morris et al., 2006; Jaffe et al., 2017). Even if plants do enrich soils in metal contaminants, there may be no consequences for co-occurring species that are likely to have some degree of metal tolerance (Morris et al., 2006; Mehdawi et al., 2011), and any impact may be greater with lower background levels of contamination (Jaffe et al., 2017).

We did detect signals that existing spatial heterogeneity in soil elemental composition influenced performance of both species independently of our experimental treatments, as indicated by plant biomass being correlated with PCA axes associated with soil heavy metals, nutrients, and organic matter. This analysis suggests that biomass in both species responds to spatial variation in nutrients, and that soil contaminants explain more variation in biomass of sugar maples than black oak. Strong spatial variation of metals in contaminated sites has been documented previously (Yang et al., 2013), including at Palmerton, where a survey of plant and soil metal concentrations in white snakeroot, autumn bent grass, and three other herbaceous species found that plant and soil metal concentration profiles were closely related, such that plant species identity explained more variation in soil metals than spatial proximity (Dietterich et al., 2017). Thus, in this study, we hypothesized stronger positive relationships between plant and soil elemental concentrations than we observed. Either black oak and sugar maple are strongly regulating elemental uptake (Baker, 1981), the total extractible pools we measured do not accurately reflect available pools (Remon et al., 2013), or close relationships between plant and soil chemistry take more than one growing season to develop (Waring et al., 2015).

Our study illustrates that the role and importance of PSF in natural systems must be evaluated in the context of other ecological processes and the background soil environment, and provides valuable information to land managers about how gray birch, as a strong colonizer, may influence succession. We found that gray birch contributes to greater species diversity initially, and we provide evidence that it favors ECM-reliant, later successional woody species like black oak. Some stakeholders express strong desire to eliminate gray birch mechanically or via controlled burns (Van Auken, 2009) because grassland habitat is rare in Pennsylvania and hosts several rare plant and insect species (Latham et al., 2007), yet controlled burns are expensive and risk releasing metals in smoke (Pereira and Úbeda, 2010; 
Abraham et al., 2017, 2018). The deciduous forest that is likely to develop, if left alone, holds similar potential for soil stabilization as grasses, but lingering high topsoil metal concentrations and potential mobilization and bio-accumulation of metals from gray birch leaves into the local food chain will still need monitoring. Herbivory by deer may compromise the return of many desirable native forest and understory species (Horsley et al., 2003; White, 2012), but we are encouraged by findings of red oak recruitment in gray birch dominated areas nearby (Cullen et al., 2016), and by coniferous and broad-leaved species coexisting with gray birch in all but the steepest, rockiest slopes of a coal mine site near Palmerton (pers. obs.). We support recent recommendations that parts of the site be allowed to return to forest while others be maintained as grassland (LGNC, 2016). This approach will provide a field laboratory to study the ecology of plant communities in heavy metal polluted soils, including roles of PSF, under two very different management regimes.

\section{DATA AVAILABILITY STATEMENT}

The raw data supporting the conclusions of this manuscript will be made available by the authors, without undue reservation, to any qualified researcher.

\section{AUTHOR CONTRIBUTIONS}

$\mathrm{LD}$ and $\mathrm{BC}$ conceived and designed the study. $\mathrm{LD}, \mathrm{AL}$, and SG performed the experiments. LD performed the

\section{REFERENCES}

Abraham, J., Dowling, K., and Florentine, S. (2017). Controlled burn and immediate mobilization of potentially toxic elements in soil, from a legacy mine site in Central Victoria, Australia. Sci. Total Environ. 616-617, 1022-1034. doi: 10.1016/j.scitotenv.2017.10.216

Abraham, J., Dowling, K., and Florentine, S. (2018). Influence of controlled burning on the mobility and temporal variations of potentially toxic metals (PTMs) in the soils of a legacy gold mine site in Central Victoria, Australia. Geoderma 331, 1-14. doi: 10.1016/j.geoderma.2018.06.010

Ayres, M. P., Clausen, T. P., Stephen F MacLean, J., Redman, A. M., and Reichardt, P. B. (1997). Diversity of structure and antiherbivore activity in condensed tannins. Ecology 78, 1696-1712. doi: 10.1890/00129658(1997)078[1696:DOSAAA]2.0.CO;2

Baker, A. (1981). Accumulators and excluders-strategies in the response of plants to heavy metals. J. Plant Nutr. 3, 643-654. doi: 10.1080/01904168109362867

Baker, A., and Brooks, R. R. (1989). Terrestrial higher plants which hyperaccumulate metallic elements - A review of their distribution, ecology and phytochemistry. Biorecovery 1, 81-126.

Barbosa, P., Hines, J., Kaplan, I., Martinson, H., Szczepaniec, A., and Szendrei, Z. (2009). Associational resistance and associational susceptibility: having right or wrong neighbors. Annu. Rev. Ecol. Evol. Syst. 40, 1-20. doi: 10.1146/annurev.ecolsys.110308.120242

Bauer, J. T., Mack, K. M. L., and Bever, J. D. (2015). Plant-soil feedbacks as drivers of succession: evidence from remnant and restored tallgrass prairies. Ecosphere 6, art158-12. doi: 10.1890/ES14-00480.1

Bennett, J. A., and Klironomos, J. (2019). Mechanisms of plant-soil feedback: interactions among biotic and abiotic drivers. New Phytol. 222, 91-96. doi: $10.1111 / \mathrm{nph} .15603$ statistical analysis with contributions from all authors and wrote the first draft of the manuscript. All authors contributed to manuscript revision, read and approved the submitted version.

\section{FUNDING}

LD was supported by fellowships from the University of Pennsylvania while conducting this study.

\section{ACKNOWLEDGMENTS}

We gratefully acknowledge the Lehigh Gap Nature Center (LGNC), in particular D. Kunkle (LGNC), D. Husic (Moravian College), and C. Root (EPA), for allowing us to conduct these experiments on the LGNC's land, as well as for abundant practical and intellectual input. We thank D. Vann (University of Pennsylvania) for sharing his extensive knowledge and help with ICP-OES measurements. We also deeply appreciate help from dozens of students, colleagues, and friends with the field and lab components of this project.

\section{SUPPLEMENTARY MATERIAL}

The Supplementary Material for this article can be found online at: https://www.frontiersin.org/articles/10.3389/fevo. 2019.00459/full\#supplementary-material
Bever, J. D., Westover, K. M., and Antonovics, J. (1997). Incorporating the soil community into plant population dynamics: the utility of the feedback approach. J. Ecol. 85:561. doi: 10.2307/2960528

Bezemer, T. M., Jing, J., Bakx-Schotman, J. M. T., and Bijleveld, E.-J. (2018). Plant competition alters the temporal dynamics of plant-soil feedbacks. J. Ecol. 106, 2287-2300. doi: 10.1111/1365-2745.12999

Blaisdell, G. K., Roy, B. A., Pfeifer-Meister, L., and Bridgham, S. D. (2015). An exploration of hypotheses that explain herbivore and pathogen attack in restored plant communities. PLoS ONE 10:e0116650. doi: 10.1371/journal.pone.0116650

Bolan, N. S., Park, J. H., Robinson, B., Naidu, R., and Huh, K. Y. (2011). Phytostabilization: a green approach to contaminant containment. Adv. Agron. 112, 145-204. doi: 10.1016/B978-0-12-385538-1.00004-4

Boyd, R. S., and Jaffré, T. (2001). Phytoenrichment of soil Ni content by Sebertia acuminata in New Caledonia and the concept of elemental allelopathy. S. Afr. J. Sci. 97, 535-538.

Boyd, R. S., and Martens, S. N. (1998). The significance of metal hyperaccumulation for biotic interactions. Chemoecology 8, 1-7. doi: $10.1007 /$ s000490050002

Broz, A. K., Broeckling, C. D., De-la-Peña, C., Lewis, M. R., Greene, E., Callaway, R. M., et al. (2010). Plant neighbor identity influences plant biochemistry and physiology related to defense. BMC Plant Biol. 10, 115-128. doi: 10.1186/1471-2229-10-115

Buchauer, M. J. (1973). Contamination of soil and vegetation near a zinc smelter by zinc, cadmium, copper, and lead. Environ. Sci. Technol. 7, 131-135. doi: 10.1021/es60074a004

Casper, B. B., and Castelli, J. P. (2007). Evaluating plant-soil feedback together with competition in a serpentine grassland. Ecol. Lett. 10, 394-400. doi: 10.1111/j.1461-0248.2007.01030.x 
Castle, S. C., Lekberg, Y., Affleck, D., and Cleveland, C. C. (2016). Soil abiotic and biotic controls on plant performance during primary succession in a glacial landscape. J. Ecol. 104, 1555-1565. doi: 10.1111/1365-2745.12615

Connell, J. H., and Slatyer, R. O. (1977). Mechanisms of succession in natural communities and their role in community stability and organization. Am. Nat. 111, 1119-1144. doi: 10.1086/283241

Cornelissen, T., Fernandes, G. W., and Vasconcellos-Neto, J. (2008). Size does matter: variation in herbivory between and within plants and the plant vigor hypothesis. Oikos 117, 1121-1130. doi: 10.1111/j.0030-1299.2008. 16588.x

Crawford, K. M., Bauer, J. T., Comita, L. S., Eppinga, M. B., Johnson, D. J., Mangan, S. A., et al. (2019). When and where plant-soil feedback may promote plant coexistence: a meta-analysis. Ecol. Lett. 17, 1613-1611. doi: 10.1111/ele.13278

Cullen, A. C., Korapati, S., Gallagher, F. J., and Holzapfel, C. (2016). "Oak succession in a pioneer forest on an urban brownfield," in 101st Annual Ecological Society of America Meeting (Fort Lauderdale, FL).

De Long, J. R., Fry, E. L., Veen, G. F., and Kardol, P. (2018). Why are plant-soil feedbacks so unpredictable, and what to do about it? Funct. Ecol. 33, 118-128. doi: $10.1111 / 1365-2435.13232$

Dickie, I. A., Koide, R. T., and Fayish, A. C. (2001). Vesicular-arbuscular mycorrhizal infection of Quercus rubra seedlings. New Phytol. 151, 257-264. doi: 10.1046/j.1469-8137.2001.00148.x

Dietterich, L. H., and Casper, B. B. (2017). Initial soil amendments still affect plant community composition after nine years in succession on a heavy metal contaminated mountainside. Restor. Ecol. 25, 201-210. doi: 10.1111/rec.12423

Dietterich, L. H., Gonneau, C., and Casper, B. B. (2017). Arbuscular mycorrhizal colonization has little consequence for plant heavy metal uptake in contaminated field soils. Ecol. Appl. 27, 1862-1875. doi: 10.1002/eap.1573

Ehrenfeld, J. G., Ravit, B., and Elgersma, K. (2005). Feedback in the plant-soil system. Annu. Rev. Environ. Resourc. 30, 75-115. doi: 10.1146/annurev.energy.30.050504.144212

EPA (2007a). Palmerton Zinc Pile: Compost/Biosolids Application To Revegetate Defoliated Areas. Palmerton, PA, 1-9.

EPA (2007b). Third Five-Year Review Report For Palmerton Zinc Pile Superfund Site. Palmerton, PA: EPA, 1-100.

Feigl, G., Molnár, Á., Szollosi, R., Ördög, A., Törocsik, K., Oláh, D., et al. (2019). Zinc-induced root architectural changes of rhizotron-grown B. napus correlate with a differential nitro-oxidative response. Nitric Oxide 90, 55-65. doi: 10.1016/j.niox.2019.06.003

Gallagher, F. J., Pechmann, I., Holzapfel, C., and Grabosky, J. (2011). Altered vegetative assemblage trajectories within an urban brownfield. Environ. Pollut. 159, 1159-1166. doi: 10.1016/j.envpol.2011.02.007

Gehring, C., and Bennett, A. (2009). Mycorrhizal fungal-plant-insect interactions: the importance of a community approach. Environ. Entomol. 38, 93-102. doi: 10.1603/022.038.0111

Harley, J. L., and Harley, E. L. (1987). A check-list of mycorrhiza in the British flora. New Phytol. 105, 1-102. doi: 10.1111/j.1469-8137.1987.tb00674.x

Heinze, J., and Joshi, J. (2017). Plant-soil feedback effects can be masked by aboveground herbivory under natural field conditions. Oecologia 186, 235-246. doi: 10.1007/s00442-017-3997-y

Heinze, J., Simons, N. K., Seibold, S., Wacker, A., Weithoff, G., Gossner, M. M., et al. (2019). The relative importance of plant-soil feedbacks for plant-species performance increases with decreasing intensity of herbivory. Oecologia 190, 651-664. doi: 10.1007/s00442-019-04442-9

Horsley, S. B., Stout, S. L., and deCalesta, D. S. (2003). White-tailed deer impact on the vegetation dynamics of a northern hardwood forest. Ecol. Appl. 13, 98-118. doi: 10.1890/1051-0761(2003)013[0098:WTDIOT]2.0.CO;2

Hortal, S., Lozano, Y. M., Bastida, F., Armas, C., Moreno, J. L., Garcia, C., et al. (2017). Plant-plant competition outcomes are modulated by plant effects on the soil bacterial community. Sci. Rep. 7:17756. doi: 10.1038/s41598-017-18103-5

Inderjit, Wardle, D. A., Karban, R., and Callaway, R. M. (2011). The ecosystem and evolutionary contexts of allelopathy. Trends Ecol. Evol. 26, 659-666. doi: 10.1016/j.tree.2011.08.003

INVAM (2014). International Culture Collection of (Vesicular) Arbuscular Mycorrhizal Fungi (INVAM). Staining of Mycorrhizal Roots. Available online at: http://invam.wvu.edu/methods/mycorrhizae/staining-roots (accessed September 13, 2016).
Jaffe, B. D., Ketterer, M. E., and Shuster, S. M. (2017). Elemental allelopathy by an arsenic hyperaccumulating fern, Pteris vittata L. J. Plant Ecol. 11, 553-559. doi: 10.1093/jpe/rtx020

Johnson, M. T. J., Bertrand, J. A., and Turcotte, M. M. (2016). Precision and accuracy in quantifying herbivory. Ecol. Entomol. 41, 112-121. doi: 10.1111/een.12280

Jordan, M. J. (1975). Effects of zinc smelter emissions and fire on a chestnut-oak woodland. Ecology 56, 78-91. doi: 10.2307/1935301

Jumpponen, A. (2001). Dark septate endophytes - are they mycorrhizal? Mycorrhiza 11, 207-211. doi: 10.1007/s005720100112

Kardol, P., Martijn Bezemer, T., and Van Der Putten, W. H. (2006). Temporal variation in plant-soil feedback controls succession. Ecol. Lett. 9, 1080-1088. doi: 10.1111/j.1461-0248.2006.00953.x

Keinänen, M., Julkunen-Tiitto, R., Rousi, M., and Tahvanainen, J. (1999). Taxonomic implications of phenolic variation in leaves of birch (Betula L.) species. Biochem. Syst. Ecol. 27, 243-254. doi: 10.1016/S0305-1978(98)00086-6

Kim, T. N. (2017). How plant neighborhood composition influences herbivory: Testing four mechanisms of associational resistance and susceptibility. PLoS ONE 12:e0176499. doi: 10.1371/journal.pone.0176499

Koricheva, J., Gange, A. C., and Jones, T. (2009). Effects of mycorrhizal fungi on insect herbivores: a meta-analysis. Ecology 90, 2088-2097. doi: $10.1890 / 08-1555.1$

Kos, M., Tuijl, M. A. B., de Roo, J., Mulder, P. P. J., and Bezemer, T. M. (2015). Species-specific plant-soil feedback effects on above-ground plantinsect interactions. J. Ecol. 103, 904-914. doi: 10.1111/1365-2745.12402

Kostenko, O., van de Voorde, T. F. J., Mulder, P. P. J., van der Putten, W. H., and Bezemer, T. M. (2012). Legacy effects of aboveground-belowground interactions. Ecol. Lett. 15, 813-821. doi: 10.1111/j.1461-0248.2012.01801.x

Krumins, J. A., Goodey, N. M., and Gallagher, F. (2015). Plant-soil interactions in metal contaminated soils. Soil Biol. Biochem. 80, 224-231. doi: 10.1016/j.soilbio.2014.10.011

Kulmatiski, A., Beard, K. H., Stevens, J. R., and Cobbold, S. M. (2008). Plant-soil feedbacks: a meta-analytical review. Ecol. Lett. 11, 980-992. doi: 10.1111/j.1461-0248.2008.01209.x

Latham, R. E., Steckel, D. B., Harper, H. M., Steckel, C., and Boatright, M. (2007). Lehigh Gap Wildlife Refuge Ecological Assessment. Media, PA; Rose Valley, PA; Allentown, PA: Natural Lands Trust; Continental Conservation; Botanical Inventory.

Lekberg, Y., Bever, J. D., Bunn, R. A., Callaway, R. M., Hart, M. M., Kivlin, S. N., et al. (2018). Relative importance of competition and plant-soil feedback, their synergy, context dependency and implications for coexistence. Ecol. Lett. 21, 1268-1281. doi: 10.1111/ele.13093

LGNC (2016). Lehigh Gap Nature Center (LGNC). Desired Future Conditions Meeting. Slatington, PA: Lehigh Gap Nature Center (LGNC).

Lozano, Y. M., Hortal, S., Armas, C., and Pugnaire, F. I. (2018). Soil microorganisms and competitive ability of a tussock grass species in a dry ecosystem. J. Ecol. 107, 1215-1225. doi: 10.1111/1365-2745.13104

Maighal, M., Salem, M., Kohler, J., and Rillig, M. C. (2016). Arbuscular mycorrhizal fungi negatively affect soil seed bank viability. Ecol. Evol. 6, 7683-7689. doi: $10.1002 /$ ece3.2491

Maunoury-Danger, F., Felten, V., Bojic, C., Fraysse, F., Ponce, M. C., DedourgeGeffard, O., et al. (2018). Metal release from contaminated leaf litter and leachate toxicity for the freshwater crustacean Gammarus fossarum. Environ. Sci. Pollut. Res. Int. 25, 11281-11294. doi: 10.1007/s11356-017-9452-0

McGonigle, T. P., Miller, M. H., Evans, D. G., Fairchild, G. L., and Swan, J. A. (1990). A new method which gives an objective measure of colonization of roots by vesicular-arbuscular mycorrhizal fungi. New Phytol. 115, 495-501. doi: 10.1111/j.1469-8137.1990.tb00476.x

Mehdawi, E.1, A. F., Quinn, C. F., and Pilon-Smits, E. A. H. (2011). Effects of selenium hyperaccumulation on plant-plant interactions: evidence for elemental allelopathy? New Phytol. 191, 120-131. doi: 10.1111/j.1469-8137.2011.03670.x

Morris, C., Call, C. A., Monaco, T. A., Grossl, P. R., and Dewey, S. A. (2006). Evaluation of elemental allelopathy in Acroptilon repens (L.) DC. (Russian Knapweed). Plant Soil 289, 279-288. doi: 10.1007/s11104-006-9136-x

Morris, C., Grossl, P. R., and Call, C. A. (2009). Elemental allelopathy: processes, progress, and pitfalls. Plant Ecol. 202, 1-11. doi: 10.1007/s11258-008-9470-6 
Pereira, P., and Úbeda, X. (2010). Spatial distribution of heavy metals released from ashes after a wildfire. J. Environ. Eng. Landsc. Manage. 18, 13-22. doi: $10.3846 /$ jeelm.2010.02

Png, G. K., Lambers, H., Kardol, P., Turner, B. L., Wardle, D. A., and Laliberté, E. (2018). Biotic and abiotic plant-soil feedback depends on nitrogen-acquisition strategy and shifts during long-term ecosystem development. J. Ecol. 107, 142-153. doi: 10.1111/1365-2745.13048

Price, P. W. (1991). The plant vigor hypothesis and herbivore attack. Oikos 62, 244. doi: $10.2307 / 3545270$

Pringle, A., Bever, J. D., Gardes, M., Parrent, J. L., Rillig, M. C., and Klironomos, J. N. (2009). Mycorrhizal symbioses and plant invasions. Annu. Rev. Ecol. Evol. Syst. 40, 699-715. doi: 10.1146/annurev.ecolsys.39.110707.173454

Rascio, N., and Navari-Izzo, F. (2011). Heavy metal hyperaccumulating plants: How and why do they do it? And what makes them so interesting? Plant Sci. 180, 169-181. doi: 10.1016/j.plantsci.2010.08.016

Remon, E., Bouchardon, J. L., Le Guédard, M., Bessoule, J. J., Conord, C., and Faure, O. (2013). Are plants useful as accumulation indicators of metal bioavailability? Environ. Pollut. 175, 1-7. doi: 10.1016/j.envpol.2012.12.015

Reynolds, H. L., Packer, A., Bever, J. D., and Clay, K. (2003). Grassroots ecology: plant-microbe-soil interactions as drivers of plant community structure and dynamics. Ecology 84, 2281-2291. doi: 10.1890/02-0298

Treseder, K. K., Mack, M. C., and Cross, A. (2004). Relationships among fires, fungi, and soil dynamics in Alaskan boreal forests. Ecol. Appl. 14, 1826-1838. doi: 10.1890/03-5133

Turnau, K., Anielska, T., Ryszka, P., Gawronski, S., Ostachowicz, B., and Jurkiewicz, A. (2008). Establishment of arbuscular mycorrhizal plants originating from xerothermic grasslands on heavy metal rich industrial wastes-new solution for waste revegetation. Plant Soil 305, 267-280. doi: 10.1007/s11104-008-9563-y

Turnau, K., Ostachowicz, B., Wojtczak, G., Anielska, T., and Sobczyk, Ł. (2010). Metal uptake by xerothermic plants introduced into $\mathrm{Zn}-\mathrm{Pb}$ industrial wastes. Plant Soil 337, 299-311. doi: 10.1007/s11104-010-0527-7

Van Auken, O. W. (2009). Causes and consequences of woody plant encroachment into western North American grasslands. J. Environ. Manage. 90, 2931-2942. doi: 10.1016/j.jenvman.2009.04.023

Van Der Putten, W. H., Bardgett, R. D., Bever, J. D., Bezemer, T. M., Casper, B. B., Fukami, T., et al. (2013). Plant-soil feedbacks: the past, the present and future challenges. J. Ecol. 101, 265-276. doi: 10.1111/1365-2745.12054

Van Der Putten, W. H., Bradford, M. A., Pernilla Brinkman, E., van de Voorde, T. F. J., and Veen, G. F. (2016). Where, when and how plant-soil feedback matters in a changing world. Funct. Ecol. 30, 1109-1121. doi: 10.1111/1365-2435.12657

Varga, S., and Kytöviita, M.-M. (2016). Faster acquisition of symbiotic partner by common mycorrhizal networks in early plant life stage. Ecosphere 7, e01222e01213. doi: 10.1002/ecs2.1222

Wang, B., and Qiu, Y. L. (2006). Phylogenetic distribution and evolution of mycorrhizas in land plants. Mycorrhiza 16, 299-363. doi: 10.1007/s00572-005-0033-6

Wang, M., Bezemer, T. M., Van Der Putten, W. H., and Biere, A. (2015). Effects of the timing of herbivory on plant defense induction and insect performance in ribwort plantain (Plantago lanceolata 1.) depend on plant mycorrhizal status. J. Chem. Ecol. 41, 1006-1017. doi: 10.1007/s10886-015-0644-0

Waring, B. G., Álvarez-Cansino, L., Barry, K. E., Becklund, K. K., Dale, S., Gei, M. G., et al. (2015). Pervasive and strong effects of plants on soil chemistry: a meta-analysis of individual plant "Zinke" effects. Proc. Biol. Sci. 282, 20151001-20151008. doi: 10.1098/rspb.2015.1001

Weiner, J., and Thomas, S. C. (1986). Size variability and competition in plant monocultures. Oikos 47, 211-222. doi: 10.2307/3566048

White, M. A. (2012). Long-term effects of deer browsing: composition, structure and productivity in a northeastern Minnesota old-growth forest. For. Ecol. Manage. 269, 222-228. doi: 10.1016/j.foreco.2011.12.043

Williams, R. J., Hallgren, S. W., Wilson, G. W. T., and Palmer, M. W. (2013). Juniperus virginiana encroachment into upland oak forests alters arbuscular mycorrhizal abundance and litter chemistry. Appl. Soil Ecol. 65, 23-30. doi: 10.1016/j.apsoil.2012.12.020

Wilson, J., and Agnew, A. (1992). Positive-feedback switches in plant communities. Adv. Ecol. Res. 23, 263-336. doi: 10.1016/S0065-2504(08)60149-X

Wubs, E. R. J., and Bezemer, T. M. (2017). Temporal carry-over effects in sequential plant-soil feedbacks. Oikos 127, 220-229. doi: 10.1111/oik.04526

Xue, W., Berendse, F., and Bezemer, T. M. (2018). Spatial heterogeneity in plantsoil feedbacks alters competitive interactions between two grassland plant species. Funct. Ecol. 32, 2085-2094. doi: 10.1111/1365-2435.13124

Yang, S., Zhou, D., Yu, H., Wei, R., and Pan, B. (2013). Distribution and speciation of metals $(\mathrm{Cu}, \mathrm{Zn}, \mathrm{Cd}$, and $\mathrm{Pb})$ in agricultural and non-agricultural soils near a stream upriver from the Pearl River, China. Environ. Pollut. 177, 64-70. doi: 10.1016/j.envpol.2013.01.044

Zarcinas, B. A., Cartwright, B., and Spouncer, L. R. (1987). Nitric acid digestion and multi-element analysis of plant material by inductively coupled plasma spectrometry. Commun. Soil Sci. Plant Anal. 18, 131-146. doi: 10.1080/00103628709367806

Zhang, H., Zhuang, X., and Chu, L. M. (2012). Plant recruitment in early development stages on rehabilitated quarries in Hong Kong. Restor. Ecol. 21, 166-173. doi: 10.1111/j.1526-100X.2012.00906.x

Zhu, F., Heinen, R., van der Sluijs, M., Raaijmakers, C., Biere, A., and Bezemer, T. M. (2018). Species-specific plant-soil feedbacks alter herbivore-induced gene expression and defense chemistry in Plantago lanceolata. Oecologia 188, 801-811. doi: 10.1007/s00442-018-4245-9

Conflict of Interest: The authors declare that the research was conducted in the absence of any commercial or financial relationships that could be construed as a potential conflict of interest.

Copyright (c) 2019 Dietterich, Li, Garvey and Casper. This is an open-access article distributed under the terms of the Creative Commons Attribution License (CC BY). The use, distribution or reproduction in other forums is permitted, provided the original author(s) and the copyright owner(s) are credited and that the original publication in this journal is cited, in accordance with accepted academic practice. No use, distribution or reproduction is permitted which does not comply with these terms. 